BMJ Open

Diabetes

Research

\& Care

\title{
Safety of add-on sulfonylurea therapy in patients with type 2 diabetes using metformin: a population-based real- world study
}

\author{
Ingrid Hougen, ${ }^{1}$ Reid H Whitlock (i) , ${ }^{2}$ Paul Komenda, ${ }^{1,2}$ Claudio Rigatto, ${ }^{1,2}$ \\ Kristin K Clemens, ${ }^{3,4}$ Navdeep Tangri (i) 1,2
}

To cite: Hougen I, Whitlock RH, Komenda P, et al. Safety of add-on sulfonylurea therapy in patients with type 2 diabetes using metformin: a population-based real-world study. BMJ Open Diab Res Care 2021;9:e002352. doi:10.1136/ bmjdrc-2021-002352

\section{- Additional supplemental material is published online only. To view, please visit the journal online (http://dx.doi. org/10.1136/bmjdrc-2021- 002352).}

Received 27 April 2021 Accepted 26 November 2021

Check for updates

\section{(C) Author(s) (or their} employer(s)) 2021. Re-use permitted under CC BY-NC. No commercial re-use. See rights and permissions. Published by BMJ.

${ }^{1}$ Department of Internal Medicine, University of Manitoba Max Rady College of Medicine, Winnipeg, Manitoba, Canada

${ }^{2}$ Chronic Disease Innovation Centre, Seven Oaks General Hospital, Winnipeg, Manitoba, Canada

${ }^{3}$ Institute for Clinical Evaluative Sciences, Toronto, Ontario, Canada

${ }^{4}$ Lawson Health Research Institute, London, Ontario, Canada

Correspondence to Reid H Whitlock; rwhitlock@sogh.mb.ca

\section{ABSTRACT}

Introduction Metformin is the initial oral

antihyperglycemic agent $(\mathrm{OHA})$ of choice for most patients with type 2 diabetes (T2D). However, more than one agent is often required for optimal glucose control. As the choice of preferred second OHAs is less well defined, we sought to compare the real-world safety of sulfonylureas to other OHAs as add-on therapy to metformin in patients with T2D. Research design and methods This retrospective cohort study included adults in Manitoba, Canada with T2D from 2006 to 2017. Using a new-user design, we divided patients who started on metformin into two groups: add-on therapy with a sulfonylurea and add-on therapy with a different OHA. Outcomes included all-cause mortality, cardiovascular events, and major hypoglycemic episodes. We calculated propensity scores and applied inverse probability of treatment weights to each individual. We compared groups using Cox proportional hazards regression and explored differences in HRs between pre2008 (acarbose, meglitinides, and thiazolidinediones) and post-2008 (dipeptidyl peptidase-4 inhibitors, glucagon-like peptide- 1 receptor agonists, and sodium-glucose linked transporter-2 inhibitors) OHAs.

Results Our cohort included 32576 individuals (28077 metformin plus sulfonylurea and 4499 metformin plus 'other'). Patients newly prescribed a sulfonylurea in the setting of metformin had a higher risk of all-cause mortality (HR 1.44, 95\% Cl 1.12 to $1.84, \mathrm{p}=0.005)$ and major hypoglycemic episodes ( $\mathrm{HR} 2.78,95 \% \mathrm{Cl} 1.66$ to $4.66, p<0.001$ ) than those prescribed an 'other' OHA. No differences in cardiovascular events were observed (HR $0.99,95 \% \mathrm{Cl} 0.81$ to $1.22, \mathrm{p}=0.92)$. In subgroup analyses, mortality and cardiovascular event risk was higher in patients prescribed sulfonylureas versus post-2008 OHAs. Conclusions Sulfonylureas as add-on therapy to metformin are associated with increased risk of all-cause mortality and major hypoglycemic episodes compared with 'other' OHAs. Post hoc analysis suggests newer OHAs may be preferred to sulfonylureas as second-line therapy for glycemic control.

\section{INTRODUCTION}

Proper glycemic control is a key component of type 2 diabetes (T2D) management, as it has been shown to reduce the incidence of

\section{Significance of this study}

What is already known about this subject?

- Current guidelines recommend metformin as initial therapy in most patients with type 2 diabetes.

- The optimal choice of a second oral antihyperglycemic agent $(\mathrm{OHA})$ in addition to metformin is less well defined, and as a result significant practice variation exists.

- Many observational studies have compared dipeptidyl peptidase-4 inhibitors with sulfonylureas when in combination with metformin and most have found lower risks of mortality and cardiovascular disease.

- However, comparisons between sulfonylureas and other OHAs in this setting are much less common.

What are the new findings?

- Patients prescribed sulfonylureas as add-on therapy to metformin had increased risk of all-cause mortality compared with those prescribed other add-on OHAs.

- Patients prescribed sulfonylureas as add-on therapy to metformin had increased risk of major hypoglycemic episodes compared with those prescribed other add-on OHAs.

> Post hoc analysis suggests newer OHAs may have lower risk of cardiovascular events compared with sulfonylureas when used as second-line therapy for glycemic control.

How might these results change the focus of research or clinical practice?

- Our study findings would suggest that in all patients with T2D, sulfonylureas are a harmful second agent for combotherapy with metformin and should not be recommended.

- Guideline statements may want to incorporate realworld effectiveness trials in their updated statements concerning second-line agent preference.

- Formal economic analyses incorporating these expected outcome differences are needed to inform policy.

microvascular and macrovascular complications. ${ }^{1}$ Some patients with T2D have adequate glycemic control with lifestyle modification alone, but most require the addition of oral antihyperglycemic agents (OHAs) and/or 
insulin. To date, at least seven different classes of OHAs have become available for the management of T2D, each with different mechanisms of action, side effects, and risk/benefit profiles. Current guidelines recommend metformin as initial therapy in most patients and suggest tailoring the choice of a second agent based on degree of hyperglycemia, risk of hypoglycemia, comorbidities (including obesity, cardiovascular disease, chronic kidney disease and hepatitis), patient preference, and access to treatment. $^{23}$

The optimal choice of a second OHA in addition to metformin is less well defined, and as a result significant practice variation exists. Sulfonylureas have been used as an OHA medication for over 60 years. They stimulate pancreatic insulin secretion, and in clinical trials have been shown to reduce glycosylated hemoglobin (A1c) by $1 \%-2 \% .{ }^{4}$ It is well known that sulfonylureas increase the risk of hypoglycemia when compared with other oral agents, ${ }^{5}$ but they remain widely prescribed as a secondline OHA added to metformin due to their low costs.

Since 2008, several new classes of OHAs, dipeptidyl peptidase-4 inhibitors (DPP4), glucagon-like peptide-1 (GLP1) receptor agonists, and sodium-glucose linked transporter-2 (SGLT2) inhibitors, have been approved for use in patients with T2D. In addition to demonstrating efficacy for short-term glycemic end points, ${ }^{6-8}$ these classes of OHAs have also been shown to be either neutral or substantially effective in reducing the risk of a composite cardiovascular outcome consisting of cardiovascular death, myocardial infarction, and stroke compared with placebo in randomized controlled trials. ${ }^{9-14}$ In these trials, newer OHAs were most often used as a second or third agent alongside metformin, but how they perform against sulfonylureas when used specifically as a second-line OHA is less well known.

Many observational studies have compared DPP4 inhibitors with sulfonylureas when in combination with metformin and most have found lower risks of mortality and cardiovascular disease. ${ }^{15-19}$ However, comparisons between sulfonylureas and other OHAs in this setting are much less common. In this observational, populationwide study, we set out to compare all-cause mortality, cardiovascular events, and major hypoglycemic episodes in patients using metformin who were newly prescribed sulfonylureas compared with other OHAs (older and newer agents) in a real-world setting.

\section{METHODS}

\section{Data sources}

Data were obtained from eight population-wide, anonymized administrative health databases in Manitoba, a Canadian province of 1.3 million people with universal single-payer health insurance. Databases analyzed include the Canadian Institute for Health Information Hospital Discharge Abstracts (hospital admissions), Diabetes Education Resource for Children and Adolescents (type of diabetes), Diagnostic Services of
Manitoba (laboratory test results), Drug Program Information Network (complete record of all outpatient drug prescriptions in Manitoba), Emergency Admission, Discharge, and Transfer/Emergency Department Information System (emergency room visits), Manitoba Health Insurance Registry (demographics and coverage dates), and Medical Claims/Services (physician claims). These databases are housed at the Repository at the Manitoba Centre for Health Policy at the University of Manitoba and cleaned according to published data quality framework. ${ }^{20-22}$ The de-identified information in each database can be linked to a unique individual through a scrambled personal health identification number. The databases and time periods used for data extraction are listed in online supplemental table 1.

\section{Study design and population}

The study period for this retrospective cohort study was from April 1, 2006 to March 31, 2017. Eligible patients were those who met one of the following criteria: at least one hospitalization with a diabetes diagnosis, at least two physician claims with a diabetes diagnosis, or at least one prescription for an OHA or insulin. We excluded patients with gestational or type 1 diabetes, and those who were under 18 years of age or had $<1$ year of history in the health insurance registry at the index date. A wash-in period of 365 days without use of any antihyperglycemic agents with the exception of metformin was required prior to filling a prescription for a new OHA. Patients needed to have evidence of metformin use at the time of their new OHA prescription. Individuals who were simultaneously prescribed two or more additional add-on OHAs on the index date were not eligible. The index date was defined as the date an individual filled an incident prescription. No restrictions were applied on the length of time on metformin treatment before add-on therapy.

OHAs were identified through their anatomic therapeutic chemical (ATC) code and date of dispensation. Online supplemental table 2 lists all of the OHAs available in our databases during the study period. Subjects were divided into two exposure groups: metformin plus sulfonylurea users (chloropropamide, gliclazide, glimepiride, glyburide, or tolbutamide) versus metformin plus 'other' OHA users (acarbose, DPP4 inhibitors, GLP1 receptor agonists, meglitinides, SGLT2 inhibitors, and thiazolidinediones (TZDs)).

Patients were followed from the index date until either the date of an outcome or the earliest censoring event. Censoring events consisted of one of: (1) a switch to or addition of insulin; (2) discontinuation of metformin or the index OHA (defined as a failure to refill before a 90-day grace period); (3) termination of insurance coverage due to migration out of province or death; (4) the end of the study period; (5) a switch to or addition of a sulfonylurea for those in the metformin plus 'other' group; or (6) a switch to or addition of another OHA in the metformin plus sulfonylurea group. We identified the days of supply for each prescription and counted 
that as the number of days with the drug in-hand while accounting for early refills, meaning that if an individual refilled a prescription before the end of their supply the excess number of days left over was carried over to the new prescription.

\section{Outcomes}

Our primary outcomes were all-cause mortality, hospitalization for fatal and non-fatal cardiovascular events, and major hypoglycemic episodes (see specific case definitions in online supplemental table 3). All-cause mortality was determined using date of death in the Manitoba Health Insurance Registry Database. A cardiovascular event was defined as the composite of acute myocardial infarction, heart failure, stroke (ischemic or hemorrhagic), or unstable angina. We only included hospitalizations for the composite outcome that was a primary discharge diagnosis and excluded International Classification of Diseases (ICD) codes that were explicitly associated with recurrent events. ${ }^{23-28}$ Major hypoglycemic episodes were defined as a presentation to the emergency room or admission to hospital with a primary or underlying diagnosis of hypoglycemia, ${ }^{29}$ or a blood glucose level of 3.5 $\mathrm{mmol} / \mathrm{L}$ or lower. ${ }^{30}$

\section{Covariates}

We collected demographics, comorbidities, and drug prescription data on patients. We obtained the postal code of an individual's residence from the health insurance registry and linked it to the most recent Canada Census data to obtain neighborhood level median income in order to estimate socioeconomic status. A single physician claim or hospitalization prior to the index date was used to identify comorbidities with a lookback period of at least 3 years (see online supplemental table 4 for ICD codes for comorbidities). We used physician claims to determine if an individual used chronic dialysis at baseline according to a validated algorithm, ${ }^{31}$ however, there were no individuals on dialysis at the index date. We checked prescriptions up to 1 year prior to the index date for selective concomitant medications indicative of the comorbidities collected. One dispensed prescription was required for an individual to be considered a user of the medication (see online supplemental table 5 for ATC codes of medications). We also derived a nominal variable ( $<1$ year; $1-3$ years; $\geq 3$ years) based on the number of years prior an individual was adherent on metformin before they added a second OHA. We used the same criteria for adherence to metformin as we did with the index OHA.

\section{Data analysis}

All analyses were performed using SAS V.9.4 (SAS Institute, Cary, North Carolina, USA). Descriptive statistics were reported for both cohorts and stratified by OHA exposure group. Categorical variables were reported as frequency and percentage. Continuous variables were reported as means plus $\mathrm{SD}$ or as median and $\mathrm{IQR}$ depending on the distribution.

We calculated the predicted probability of being assigned a sulfonylurea (propensity score) using binary logistic regression based on baseline covariates for pairwise comparisons in our cohorts. We used a nonparsimonious approach in our propensity score models. Age, sex, socioeconomic status, index fiscal year, time spent on metformin, and the concomitant medications and comorbidities we collected at baseline were included as covariates.

We evaluated the performance of the propensity score models with $\mathrm{C}$ statistics and the rescaled maximum $\mathrm{R}^{2}$. We assessed for multicollinearity among covariates by creating a linear regression model where the propensity score was the dependent variable. We considered variance inflation $>10$ as our threshold to remove a covariate from the final propensity score model. We used the propensity score to calculate a stabilized inverse probability of treatment weight (IPTW) ${ }^{32}$ and applied the weight to each individual. We diagnosed balance pre-IPTW and post-IPTW by calculating a standardized mean difference (SMD) to compare the distribution of baseline covariates between treatment groups. An SMD with a magnitude of 0.10 or less was considered to be balanced. ${ }^{33}$

We then constructed a series of Cox proportional hazards regression models to analyze time to event for each of the proposed safety outcomes comparing those newly prescribed sulfonylureas versus 'other' OHAs while adjusting for a stabilized IPTW. The proportional hazards assumption was assessed by the Kolmogorov-type supremum test. ${ }^{34}$ The assumption was met for all Cox proportional hazards regression models. We reported HRs with $95 \%$ CIs and $\mathrm{p}$ values for each of the safety outcomes. We also reported cumulative incidence functions for each of the safety outcomes using Kaplan-Meier estimates and compared the results for each OHA group using the log-rank test.

\section{Sensitivity and subgroup analysis}

As a sensitivity analysis, we log-transformed the propensity score and matched new sulfonylureas users to 'other' OHA 1:1 based on their nearest neighbor within a caliper distance of 0.2 SD of the logit of the propensity score. ${ }^{35} 36$ We conducted survival analysis with Cox proportional hazards regression models in that cohort as well and accounted for matching by stratifying by matched pairs. To address the issue of informative censoring bias, we also investigated a scenario where we did not censor for adding other antidiabetic drugs including insulin to the existing regimen to see if the results would be significantly changed. We limited our follow-up to 2 years in this intention-to-treat analysis to reduce the risk of exposure misclassification. As a final sensitivity analysis, we limited the grace period between prescriptions to 30 days before censoring due to discontinuation.

As a post hoc subgroup analysis, we divided our 'other' OHAs into two groups reflecting the era of when they 


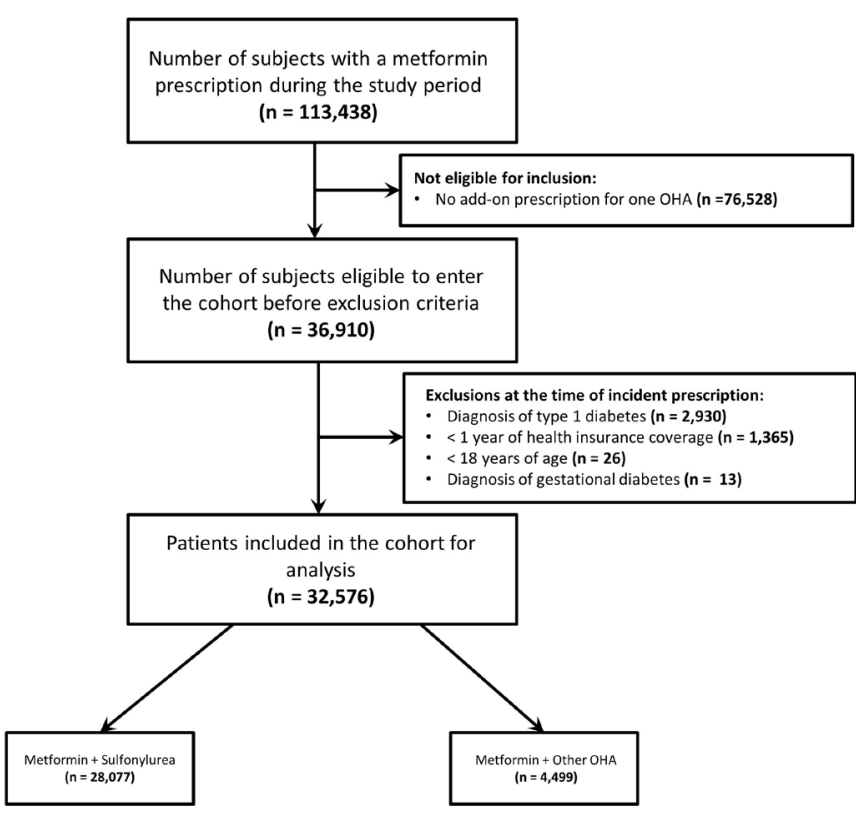

Figure 1 Cohort selection. OHA, oral antihyperglycemic agent.

became available for prescription. Acarbose, meglitinides, and TZDs comprised the pre-2008 group and DPP4 inhibitors, GLP1 receptor agonists, and SGLT2 inhibitors comprised the post-2008 group. We chose 2008 as a cut-off as it corresponded to use of distinct classes of OHAs with a reduced overlap period. We performed additional Cox proportional hazards regression models comparing sulfonylureas with each subgroup for all of our outcomes while adjusting for stabilized IPTW.

\section{RESULTS}

Study population

We identified 32576 metformin users with T2D who had an incident OHA prescription between April 1, 2006 and March 31, 2017 (figure 1). Of those, 28077 were newly prescribed a sulfonylurea and 4499 were prescribed an 'other' OHA. Prior to matching, the 'other' OHA group included patients prescribed DPP4 inhibitors (36.2\%), TZDs $(27.4 \%)$, SGLT2 inhibitors $(20.8 \%)$, meglitinides $(9.4 \%)$, GLP1 receptor agonists $(4.0 \%)$, and acarbose $(2.2 \%)$. Among patients prescribed a sulfonylurea, 18800 $(67.0 \%)$ were prescribed gliclazide, $9139(32.5 \%)$ were prescribed glyburide, and $138(0.5 \%)$ were prescribed a different sulfonylurea. At baseline, both groups had similar demographics and comorbidity and medication profiles. However, patients in the sulfonylurea group were more likely to be of lower socioeconomic status, have filled their prescription in an earlier era, and spent less time on metformin before add-on therapy (table 1).

\section{Propensity score analysis}

The logistic regression model used to derive the propensity score achieved a $\mathrm{C}$ statistic of 0.68 and $\mathrm{R}^{2}$ of $8.5 \%$ and there was no evidence of multicollinearity. Groups were well balanced on IPTW (table 2). Mean age in the sulfonylurea group was $56.4 \pm 14.0$ years whereas the 'other' group had a mean age of $56.8 \pm 13.3$ years. Both groups weighted by IPTW were $44 \%$ female. All other baseline characteristics were balanced (SMD <0.1). The 1:1 propensity matching algorithm matched 4499 combotherapy sulfonylurea users to all 4499 combotherapy 'other' OHA users. After propensity matching, the sulfonylurea and 'other' combotherapy groups were similar in age, gender, socioeconomic status, comorbid conditions, and baseline medications (online supplemental table 6).

\section{Cox regression models}

There were a total of 838 deaths, 836 cardiovascular events, 359 major hypoglycemic episodes, and a mean follow-up time of $1.7 \pm 1.9$ years (median: 0.9 , IQR: $0.4,2.3$ ) in the metformin plus sulfonylurea group and 44 deaths, 78 cardiovascular events, 9 major hypoglycemic episodes and a mean follow-up time of $1.2 \pm 1.4$ years (median: 0.7, IQR: $0.3,1.5$ ) in the metformin plus 'other' group. After adjusting for IPTW, new users of sulfonylureas had a higher risk of all-cause mortality (HR 1.44, 95\% CI 1.12 to $1.84 ; \mathrm{p}=0.005$ ) and major hypoglycemic episodes (HR $2.78,95 \%$ CI 1.66 to 4.66 ; $\mathrm{p}<0.001$ ) when compared with 'other' OHAs combined with metformin (table 3). Sulfonylurea use was not associated with a higher risk for cardiovascular events (HR $0.99,95 \%$ CI 0.81 to $1.22 ; p=0.92$ ) compared with 'other' OHAs. Findings were qualitatively unchanged in the propensity-matched analysis, when the grace period for discontinuation was limited to 30 days, and when adding additional antidiabetic drug(s) to the existing regimen was not considered a censoring event where 7805 subjects $(24.0 \%)$ were originally censored for that reason.

\section{Subgroup analyses}

There were clear differences in HRs when the 'other' OHAs were divided into classes approved before and after 2008 (table 3). Patients who were prescribed sulfonylureas compared with pre-2008 'other' OHAs $(70.3 \%$ TZDs, $24.1 \%$ meglitinides, $5.6 \%$ acarbose) were at lower risk of cardiovascular events (HR $0.74,95 \%$ CI 0.57 to $0.95 ; \mathrm{p}=0.019$ ) and were not associated with an increased risk of all-cause mortality (HR $0.87,95 \%$ CI 0.66 to 1.15 ; $\mathrm{p}=0.32$ ). By contrast, when compared with post-2008 'other' OHAs (59.3\% DPP4 inhibitors, 34.1\% SGLT2 inhibitors, $6.6 \%$ GLP1 receptor agonists), sulfonylureas were associated with a higher risk of cardiovascular events (HR 1.40, 95\% CI 1.01 to $1.89 ; \mathrm{p}=0.041$ ) and a higher risk of death (HR 3.33, 95\% CI 2.02 to 5.49; p<0.001). There were an insufficient number of major hypoglycemic episodes to conduct a pre-2008/post-2008 analysis for this outcome.

\section{DISCUSSION}

In this observational cohort study of 32576 patients with T2D using metformin, we found that patients newly prescribed a sulfonylurea had a $40 \%$ higher risk 
Table 1 Baseline characteristics by combotherapy group (full cohort)

\begin{tabular}{|c|c|c|c|}
\hline \multirow[b]{2}{*}{ Characteristic } & \multirow{2}{*}{$\begin{array}{l}\text { Sulfonylurea } \\
(n=28077)\end{array}$} & \multirow{2}{*}{$\begin{array}{l}\text { 'Other' } \\
(n=4499) \\
\end{array}$} & \multirow[b]{2}{*}{ SMD } \\
\hline & & & \\
\hline \multicolumn{4}{|l|}{ Demographics } \\
\hline Age (years) & $56.4 \pm 14.1$ & $56.3 \pm 12.6$ & 0.007 \\
\hline Sex (\% female) & $12240(43.6 \%)$ & $2010(44.7 \%)$ & 0.022 \\
\hline \multicolumn{4}{|l|}{ Geographic/Socioeconomic status } \\
\hline Rural/Income quintile 1 & $3576(12.7 \%)$ & 275 (6.1\%) & 0.228 \\
\hline Rural/Income quintile 2 & $2616(9.3 \%)$ & $279(6.2 \%)$ & 0.117 \\
\hline Rural/Income quintile 3 & 2205 (7.9\%) & $287(6.4 \%)$ & 0.057 \\
\hline Rural/Income quintile 4 & $2081(7.4 \%)$ & $313(7.0 \%)$ & 0.017 \\
\hline Rural/Income quintile 5 & $1684(6.0 \%)$ & $328(7.3 \%)$ & 0.052 \\
\hline Urban/Income quintile 1 & $4175(14.9 \%)$ & $508(11.3 \%)$ & 0.106 \\
\hline Urban/Income quintile 2 & $3520(12.5 \%)$ & $625(13.9 \%)$ & 0.04 \\
\hline Urban/Income quintile 3 & $3127(11.1 \%)$ & $611(13.6 \%)$ & 0.074 \\
\hline Urban/Income quintile 4 & $2752(9.8 \%)$ & $643(14.3 \%)$ & 0.138 \\
\hline Urban/Income quintile 5 & $2020(7.2 \%)$ & $607(13.5 \%)$ & 0.208 \\
\hline Unknown & $321(1.1 \%)$ & $23(0.5 \%)$ & 0.07 \\
\hline \multicolumn{4}{|l|}{ Baseline comorbidities } \\
\hline Alcohol abuse & $1151(4.1 \%)$ & $75(1.7 \%)$ & 0.146 \\
\hline Amputation & $107(0.4 \%)$ & $9(0.2 \%)$ & 0.034 \\
\hline Asthma & $3900(13.9 \%)$ & $695(15.4 \%)$ & 0.044 \\
\hline CKD & $793(2.8 \%)$ & $100(2.2 \%)$ & 0.038 \\
\hline COPD & $2858(10.2 \%)$ & $382(8.5 \%)$ & 0.058 \\
\hline Cardiovascular disease & $7332(26.1 \%)$ & $1066(23.7 \%)$ & 0.056 \\
\hline Dementia & $916(3.3 \%)$ & $92(2.0 \%)$ & 0.076 \\
\hline Hypertension & $17943(63.9 \%)$ & $3006(66.8 \%)$ & 0.061 \\
\hline Hyperlipidemia & $9668(34.4 \%)$ & 1769 (39.3\%) & 0.101 \\
\hline Liver disease & $1617(5.8 \%)$ & $284(6.3 \%)$ & 0.023 \\
\hline Malignancy & $2858(10.2 \%)$ & $453(10.1 \%)$ & 0.004 \\
\hline Microvascular disease & $6178(22.0 \%)$ & $997(22.2 \%)$ & 0.004 \\
\hline Obesity & $1878(6.7 \%)$ & $364(8.1 \%)$ & 0.054 \\
\hline \multicolumn{4}{|l|}{ Baseline medication use } \\
\hline ACE inhibitors & 11491 (40.9\%) & $1753(39.0 \%)$ & 0.04 \\
\hline Anticoagulants & $1227(4.4 \%)$ & $173(3.8 \%)$ & 0.026 \\
\hline Antiplatelets & $5559(19.8 \%)$ & $661(14.7 \%)$ & 0.135 \\
\hline ARBs & $5461(19.5 \%)$ & $1085(24.1 \%)$ & 0.113 \\
\hline Beta-blockers & $5882(20.9 \%)$ & $903(20.1 \%)$ & 0.022 \\
\hline CCBs & $5388(19.2 \%)$ & $881(19.6 \%)$ & 0.01 \\
\hline Digoxin & $627(2.2 \%)$ & $77(1.7 \%)$ & 0.038 \\
\hline Direct vasodilators & $52(0.2 \%)$ & $9(0.2 \%)$ & 0.003 \\
\hline Loop diuretics & 2257 (8.0\%) & 307 (6.8\%) & 0.046 \\
\hline Potassium-sparing diuretics & $448(1.6 \%)$ & $76(1.7 \%)$ & 0.007 \\
\hline Thiazide diuretics & 4147 (14.8\%) & 615 (13.7\%) & 0.032 \\
\hline Statins & $13785(49.1 \%)$ & $2432(54.1 \%)$ & 0.099 \\
\hline Other lipid-lowering medications & 1756 (6.3\%) & $335(7.4 \%)$ & 0.047 \\
\hline
\end{tabular}


Table 1 Continued

\begin{tabular}{|c|c|c|c|}
\hline & Sulfonylurea & 'Other' & \\
\hline Characteristic & $(n=28077)$ & $(n=4499)$ & SMD \\
\hline $2006 / 07$ & 2321 (8.3\%) & 584 (13.0\%) & 0.153 \\
\hline $2007 / 08$ & 2090 (7.4\%) & 375 (8.3\%) & 0.033 \\
\hline 2008/09 & 2223 (7.9\%) & 263 (5.8\%) & 0.082 \\
\hline $2009 / 10$ & 2490 (8.9\%) & 295 (6.6\%) & 0.087 \\
\hline $2010 / 11$ & 2714 (9.7\%) & 247 (5.5\%) & 0.158 \\
\hline $2011 / 12$ & 2865 (10.2\%) & 253 (5.6\%) & 0.17 \\
\hline $2012 / 13$ & 2638 (9.4\%) & 297 (6.6\%) & 0.103 \\
\hline $2013 / 14$ & 2762 (9.8\%) & $271(6.0 \%)$ & 0.141 \\
\hline $2014 / 15$ & 2848 (10.1\%) & 468 (10.4\%) & 0.009 \\
\hline $2015 / 16$ & 2899 (10.3\%) & 853 (19.0\%) & 0.246 \\
\hline $2016 / 17$ & 2227 (7.9\%) & 593 (13.2\%) & 0.171 \\
\hline \multicolumn{4}{|c|}{ Time on metformin before add-on therapy } \\
\hline$\geq 3$ years & $6976(24.8 \%)$ & $1339(29.8 \%)$ & 0.111 \\
\hline $1-3$ years & $5892(21.0 \%)$ & $1146(25.5 \%)$ & 0.106 \\
\hline$<1$ year & 15209 (55.6\%) & 2014 (44.8\%) & 0.189 \\
\hline
\end{tabular}

$\mathrm{ARB}$, angiotensin receptor blocker; $\mathrm{CCB}$, calcium channel blocker; CKD, chronic kidney disease; COPD, chronic obstructive pulmonary disease; SMD, standardized mean difference.

of all-cause mortality and, a nearly threefold higher risk of major hypoglycemic episodes compared with those prescribed 'other' OHAs as a second-line agent. There were no differences in risk of cardiovascular events between the two groups, however, a post hoc analysis found new sulfonylurea users had a $40 \%$ higher risk of cardiovascular events versus those prescribed newer OHAs. Taken together, these results raise real-world safety concerns with the use of sulfonylureas compared with newer OHAs.

Our study findings are consistent with recent retrospective studies from the UK, Sweden, Taiwan, and Korea that evaluated the safety of sulfonylureas compared with DPP4 inhibitors when added on to metformin. ${ }^{15-19}$ In two cohort studies using the UK Clinical Practice Research Datalink, investigators noted an increased risk of cardiovascular-related and all-cause mortality in patients prescribed sulfonylureas. Similarly, in three independent analyses from Sweden, Taiwan, and Korea, an increased risk of mortality, cardiovascular events, and hypoglycemia was noted in patients prescribed sulfonylureas. Compared with these studies however, our study population was more racially diverse. We also used IPTW analysis, which requires fewer distributional assumptions about underlying data, avoids potential residual confounding from stratification on a fixed number of strata, and allowed us to capture more people than propensity matching. ${ }^{37}$ Additionally, we included a broader definition of severe hypoglycemia by using emergency room visits and lab values, and collected more information on comorbid conditions and baseline medications to add to the propensity score.
Our study also included patients on novel OHAs other than DPP4 inhibitors. While study numbers were not large enough to allow analysis of individual medication classes, DPP4 inhibitors represented a plurality of the OHAs in the 'other' group and therefore had the greatest influence in their comparison with sulfonylureas in our study. Currently, studies directly comparing sulfonylureas to OHAs other than DPP4 inhibitors as add-on therapy to metformin are limited. A recent study in the UK Clinical Practice Research Datalink ${ }^{38}$ compared cardiovascular outcomes with add-on therapy and found a lower risk of cardiovascular disease or cardiovascular death with TZDs compared with sulfonylureas. This contrasts with our results when 'other' OHAs are stratified by era and may be due to the fact that unlike our study, the UK investigators did not include heart failure among the possible cardiovascular outcomes. This may bias results in favor of TZDs as TZDs have been independently associated with heart failure due to fluid retention. ${ }^{39}$

Ekström et $a t^{40}$ studied add-on OHAs comparing sulfonylureas to TZDs, meglitinide, DPP4 inhibitors, GLP1 receptor agonists, acarbose, as well as insulin, in a Swedish population. Similar to our study, they calculated a stabilized IPTW and used it in weighted Cox models to analyze comparative risk mortality and cardiovascular events. However, they did not examine the risk of major hypoglycemic episodes, they could not include patients using SGLT2 inhibitors, and the sample for each OHA class they used for comparison was at least $36 \%$ smaller than our group of all other OHAs combined. Additionally, this study excluded patients who were on metformin for fewer than 180 days prior to add-on therapy and who 
Table 2 Baseline characteristics by combotherapy group (weighted cohort)

\begin{tabular}{|c|c|c|c|}
\hline \multirow[b]{2}{*}{ Characteristic } & Sulfonylurea & 'Other' & \multirow[b]{2}{*}{ SMD } \\
\hline & $(n=28077)$ & $(n=4499)$ & \\
\hline \multicolumn{4}{|l|}{ Demographics } \\
\hline Age (years) & $56.4 \pm 14.0$ & $56.8 \pm 13.3$ & 0.029 \\
\hline Sex (\% female) & $43.80 \%$ & $44.00 \%$ & 0.004 \\
\hline \multicolumn{4}{|c|}{$\begin{array}{l}\text { Geographic/ } \\
\text { Socioeconomic status }\end{array}$} \\
\hline $\begin{array}{l}\text { Rural/Income } \\
\text { quintile } 1\end{array}$ & $11.80 \%$ & $11.50 \%$ & 0.008 \\
\hline $\begin{array}{l}\text { Rural/Income } \\
\text { quintile } 2\end{array}$ & $8.90 \%$ & $9.50 \%$ & 0.017 \\
\hline $\begin{array}{l}\text { Rural/Income } \\
\text { quintile } 3\end{array}$ & $7.60 \%$ & $7.60 \%$ & 0.001 \\
\hline $\begin{array}{l}\text { Rural/Income } \\
\text { quintile } 4\end{array}$ & $7.30 \%$ & $7.40 \%$ & 0.003 \\
\hline $\begin{array}{l}\text { Rural/Income } \\
\text { quintile } 5\end{array}$ & $6.20 \%$ & $6.10 \%$ & 0.001 \\
\hline $\begin{array}{l}\text { Urban/Income } \\
\text { quintile } 1\end{array}$ & $14.40 \%$ & $14.20 \%$ & 0.005 \\
\hline $\begin{array}{l}\text { Urban/Income } \\
\text { quintile } 2\end{array}$ & $12.70 \%$ & $12.40 \%$ & 0.008 \\
\hline $\begin{array}{l}\text { Urban/Income } \\
\text { quintile } 3\end{array}$ & $11.50 \%$ & $11.40 \%$ & 0.002 \\
\hline $\begin{array}{l}\text { Urban/Income } \\
\text { quintile } 4\end{array}$ & $10.40 \%$ & $10.40 \%$ & $<0.001$ \\
\hline $\begin{array}{l}\text { Urban/Income } \\
\text { quintile } 5\end{array}$ & $8.10 \%$ & $8.30 \%$ & 0.007 \\
\hline Unknown & $1.10 \%$ & $1.10 \%$ & 0.005 \\
\hline \multicolumn{4}{|c|}{ Baseline comorbidities } \\
\hline Alcohol abuse & $3.80 \%$ & $3.70 \%$ & $<0.001$ \\
\hline Amputation & $0.40 \%$ & $0.40 \%$ & $<0.001$ \\
\hline Asthma & $14.10 \%$ & $13.20 \%$ & 0.02 \\
\hline CKD & $2.80 \%$ & $3.00 \%$ & 0.013 \\
\hline COPD & $10.00 \%$ & $9.70 \%$ & 0.008 \\
\hline $\begin{array}{l}\text { Cardiovascular } \\
\text { disease }\end{array}$ & $25.80 \%$ & $26.20 \%$ & 0.009 \\
\hline Dementia & $3.10 \%$ & $3.20 \%$ & 0.004 \\
\hline Hypertension & $64.30 \%$ & $65.10 \%$ & 0.013 \\
\hline Hyperlipidemia & $35.10 \%$ & $35.10 \%$ & $<0.001$ \\
\hline Liver disease & $5.80 \%$ & $6.00 \%$ & 0.005 \\
\hline Malignancy & $10.20 \%$ & $10.60 \%$ & 0.01 \\
\hline $\begin{array}{l}\text { Microvascular } \\
\text { disease }\end{array}$ & $22.00 \%$ & $22.10 \%$ & 0.001 \\
\hline Obesity & $6.90 \%$ & $6.40 \%$ & 0.016 \\
\hline \multicolumn{4}{|c|}{$\begin{array}{l}\text { Baseline medication } \\
\text { use }\end{array}$} \\
\hline ACE inhibitors & $40.70 \%$ & $40.90 \%$ & 0.004 \\
\hline Anticoagulants & $4.30 \%$ & $4.50 \%$ & 0.009 \\
\hline Antiplatelets & $19.10 \%$ & $18.90 \%$ & 0.005 \\
\hline ARBs & $20.10 \%$ & $20.60 \%$ & 0.009 \\
\hline Beta-blockers & $20.80 \%$ & $21.40 \%$ & 0.012 \\
\hline CCBs & $19.30 \%$ & $19.90 \%$ & 0.014 \\
\hline Digoxin & $2.20 \%$ & $2.20 \%$ & 0.004 \\
\hline
\end{tabular}

Continued
Table 2 Continued

\begin{tabular}{|c|c|c|c|}
\hline & Sulfonylurea & 'Other' & \\
\hline Characteristic & $(n=28077)$ & $(n=4499)$ & SMD \\
\hline Direct vasodilators & $0.20 \%$ & $0.20 \%$ & 0.002 \\
\hline Loop diuretics & $7.90 \%$ & $8.30 \%$ & 0.012 \\
\hline $\begin{array}{l}\text { Potassium-sparing } \\
\text { diuretics }\end{array}$ & $1.60 \%$ & $1.60 \%$ & 0.001 \\
\hline Thiazide diuretics & $14.60 \%$ & $14.70 \%$ & 0.001 \\
\hline Statins & $49.80 \%$ & $49.90 \%$ & 0.002 \\
\hline $\begin{array}{l}\text { Other lipid-lowering } \\
\text { medications }\end{array}$ & $6.40 \%$ & $6.20 \%$ & 0.006 \\
\hline \multicolumn{4}{|l|}{ Index fiscal year } \\
\hline $2006 / 07$ & $9.00 \%$ & $9.80 \%$ & 0.025 \\
\hline $2007 / 08$ & $7.60 \%$ & $8.00 \%$ & 0.013 \\
\hline $2008 / 09$ & $7.60 \%$ & $7.70 \%$ & $<0.001$ \\
\hline $2009 / 10$ & $8.50 \%$ & $8.90 \%$ & 0.01 \\
\hline $2010 / 11$ & $9.10 \%$ & $8.70 \%$ & 0.012 \\
\hline $2011 / 12$ & $9.60 \%$ & $9.20 \%$ & 0.011 \\
\hline $2012 / 13$ & $9.00 \%$ & $9.00 \%$ & $<0.001$ \\
\hline $2013 / 14$ & $9.30 \%$ & $8.80 \%$ & 0.014 \\
\hline $2014 / 15$ & $10.20 \%$ & $10.10 \%$ & 0.003 \\
\hline $2015 / 16$ & $11.50 \%$ & $11.20 \%$ & 0.009 \\
\hline $2016 / 17$ & $8.70 \%$ & $8.60 \%$ & $<0.001$ \\
\hline \multicolumn{4}{|l|}{$\begin{array}{l}\text { Time on metformin } \\
\text { before add-on therapy }\end{array}$} \\
\hline$\geq 3$ years & $25.50 \%$ & $25.90 \%$ & 0.006 \\
\hline $1-3$ years & $21.60 \%$ & $21.80 \%$ & 0.003 \\
\hline$<1$ year & $52.90 \%$ & $52.40 \%$ & 0.008 \\
\hline
\end{tabular}

ARB, angiotensin receptor blocker; CCB, calcium channel blocker; CKD, chronic kidney disease; COPD, chronic obstructive pulmonary disease; SMD, standardized mean difference.

had fewer than 180 days follow-up on the add-on therapy itself. This may have produced different results than what would have occurred had this criteria not been applied, as patients who initiated add-on therapy prior to 180 days may have been systematically more likely to be prescribed a sulfonylurea and those who stopped their combotherapy regimen before 180 days may be more likely to be using another OHA as seen in our data.

In our study, prescriptions for sulfonylureas as add-on therapy to metformin increased every fiscal year, and represented $77 \%$ of all add-on OHA prescriptions in the most recent fiscal year. Reasons for this may include physician familiarity with the medication given its long history and its preeminence in previous guidelines ${ }^{41}$ as well as cost associated with some of the other OHAs which may be prohibitive to patients and not universally reimbursed by private drug plans. ${ }^{42}$ Currently, sulfonylureas are listed in all Canadian provincial drug formularies for coverage in public drug plans, which is not the case for any other OHA other than metformin. Additionally, sulfonylureas are effective medications in terms of lowering A1c with meta-analyses showing A1c reductions between $0.9 \%$ and $1.62 \%$, as add-on therapy to metformin. ${ }^{43}$ This reduction 
Table 3 HRs with 95\% Cls and p values of Cox proportional hazards regression models for sulfonylurea versus other OHAs

Outcomes

\begin{tabular}{|c|c|c|c|c|c|c|}
\hline \multirow[b]{2}{*}{ Model type } & \multicolumn{2}{|c|}{ All-cause mortality } & \multicolumn{2}{|c|}{ Cardiovascular events } & \multicolumn{2}{|c|}{$\begin{array}{l}\text { Major hypoglycemic } \\
\text { episodes }\end{array}$} \\
\hline & $\begin{array}{l}\text { HR } \\
(95 \% \mathrm{Cl})\end{array}$ & $P$ value & $\begin{array}{l}\text { HR } \\
(95 \% \mathrm{Cl})\end{array}$ & $P$ values & $\begin{array}{l}\text { HR } \\
(95 \% \mathrm{Cl})\end{array}$ & $P$ values \\
\hline Unadjusted & $\begin{array}{l}2.23 \\
\text { (1.65 to } 3.03)\end{array}$ & $<0.001$ & $\begin{array}{l}1.29 \\
(1.02 \text { to } 1.63)\end{array}$ & 0.031 & $\begin{array}{l}4.72 \\
(2.43 \text { to } 9.15)\end{array}$ & $<0.001$ \\
\hline IPTW & $\begin{array}{l}1.44 \\
(1.12 \text { to } 1.84)\end{array}$ & 0.005 & $\begin{array}{l}0.99 \\
(0.81 \text { to } 1.22)\end{array}$ & 0.92 & $\begin{array}{l}2.78 \\
\text { (1.66 to } 4.66)\end{array}$ & $<0.001$ \\
\hline Propensity matched & $\begin{array}{l}2.25 \\
\text { (1.39 to } 3.64)\end{array}$ & $<0.001$ & $\begin{array}{l}0.78 \\
\text { (0.52 to } 1.19)\end{array}$ & 0.25 & $\begin{array}{l}3.50 \\
(1.15 \text { to } 10.63)\end{array}$ & 0.027 \\
\hline $\begin{array}{l}\text { IPTW (no censoring } \\
\text { for insulin or additional } \\
\text { OHAs) }\end{array}$ & $\begin{array}{l}1.35 \\
(1.03 \text { to } 1.77)\end{array}$ & 0.028 & $\begin{array}{l}1.00 \\
(0.79 \text { to } 1.26)\end{array}$ & 1.00 & $\begin{array}{l}2.88 \\
(1.62 \text { to } 5.10)\end{array}$ & $<0.001$ \\
\hline $\begin{array}{l}\text { IPTW (censoring after } \\
\text { 30-day grace period) }\end{array}$ & $\begin{array}{l}1.73 \\
\text { (1.26 to } 2.34)\end{array}$ & $<0.001$ & $\begin{array}{l}1.11 \\
\text { (0.86 to } 1.42)\end{array}$ & 0.42 & $\begin{array}{l}3.75 \\
(1.90 \text { to } 7.39)\end{array}$ & $<0.001$ \\
\hline \multicolumn{7}{|l|}{$\begin{array}{l}\text { Stratified by era using } \\
\text { IPTW }\end{array}$} \\
\hline $\begin{array}{l}\text { Sulfonylurea versus } \\
\text { pre-2008 OHAs }\end{array}$ & $\begin{array}{l}0.87 \\
(0.66 \text { to } 1.15)\end{array}$ & 0.32 & $\begin{array}{l}0.74 \\
(0.57 \text { to } 0.95)\end{array}$ & 0.019 & & \\
\hline $\begin{array}{l}\text { Sulfonylurea versus } \\
\text { post-2008 OHAs }\end{array}$ & $\begin{array}{l}3.33 \\
(2.02 \text { to } 5.49)\end{array}$ & $<0.001$ & $\begin{array}{l}1.40 \\
\text { (1.01 to } 1.93)\end{array}$ & 0.041 & & \\
\hline
\end{tabular}

IPTW, inverse probability of treatment weight; OHA, oral antihyperglycemic agent.

is not necessarily unique to sulfonylureas, however, as shown in a recent systematic review which found no statistically significant difference in Alc reduction between sulfonylureas and DPP4 inhibitors as combotherapy agents (mean pooled $0.6 \%$ reduction with DPP 4 vs $0.7 \%$ at 52 weeks with sulfonylureas). ${ }^{44}$

The evidence showing increased cardiovascular risks with sulfonylureas may be particularly relevant for patients with established cardiovascular disease or increased cardiovascular risk factors, as oral agents that provide a cardiovascular benefit are now available. Since 2008, the United States Food and Drug Administration has required that new OHAs demonstrate cardiovascular safety prior to approval, and as a result newer agents including the GLP1 receptor agonists liraglutide and semiglutide, and the SGLT2 inhibitors canagliflozin, dapagliflozin, and empagliflozin have been shown to have cardiovascular benefits in large, well-conducted randomized controlled trials which are congruent with our findings. ${ }^{10-1445}$ Current guidelines suggest that in patients with clinical cardiovascular disease in whom glycemic targets are not met, an OHA with cardiovascular benefit should be added. ${ }^{23}$ Our study findings would suggest that in all patients with T2D, sulfonylureas are a harmful second agent for combotherapy with metformin and should not be recommended.

Sulfonylureas are insulin secretagogues, a class of drugs that bind to sulfonylurea receptors on pancreatic beta-cells and stimulate insulin release. It has been posited that sulfonylureas are associated with weight gain and major hypoglycemia episodes through this mechanism since the insulin secretion is independent of plasma glucose concentrations. ${ }^{46}$ The insulin is released by inhibiting ATP-sensitive potassium channels, which impair ischemic preconditioning and increases infarct size. ${ }^{47}$ The increased risk for hypoglycemia and weight gain, and inhibition of ischemic preconditioning may explain why an increase in all-cause mortality was observed among sulfonylurea users. ${ }^{4-50}$ While no OHA is without its own side-effect profile, sulfonylureas certainly appear to carry greater risk of important safety outcomes including mortality and hypoglycemia without the benefit seen in large randomized controlled trials with newer agents such as GLP1 receptor agonists and SGLT2 inhibitors.

Our study has several strengths. First, we used large administrative databases that contained populationlevel data since every member of the cohort was covered under the same universal health insurance program. This allowed us to capture all possible exposures and outcomes in our study population. Furthermore, most observational studies that compare the safety of combotherapy regimens in patients with T2D use propensity score matching to account for confounding which leads to eliminating individuals from the analysis, whereas our study conducted our primary analysis using stabilized IPTW and as a result no individuals in our cohort were excluded from analysis. Finally, $<1 \%$ of individuals in our cohort were lost to follow-up and therefore any missed events during the study period would be minimal. 
Our study also has limitations. First, our results may not be generalizable to patients who need more than two OHAs for optimal glycemic control. Second, despite controlling for many factors, we could not fully control for important clinical variables such as blood pressure, body mass index, diabetes duration, and laboratory results. Nevertheless, many of the characteristics we collected at baseline were representative of these variables. Residual confounding is also always possible in observational studies. However, the fact that we observed harm with sulfonylurea use when compared with newer OHAs, and no difference when compared with older OHAs would argue against residual confounding, which would not be affected by era. Finally, our study numbers precluded the ability to analyze sulfonylureas compared with each subgroup of 'other' OHAs separately and findings from the subgroup analyses we did undertake were post hoc, which may reduce the strength of their evidence.

\section{CONCLUSIONS}

In conclusion, patients prescribed sulfonylureas as add-on therapy to metformin had increased risk of all-cause mortality and major hypoglycemic events compared with those prescribed other add-on OHAs. Post hoc analysis suggests that newer OHAs may be preferred to sulfonylureas as second-line therapy for glycemic control. Guidelines statements may want to incorporate real-world effectiveness trials in their updated statements concerning second-line agent preference. Formal economic analyses incorporating these expected outcomes differences are needed to inform policy.

Acknowledgements This work was supported through funding provided by the Department of Health of the Province of Manitoba to the University of Manitoba (HIPC\# 2016/2017-03). The results and conclusions are those of the authors and no official endorsement by Manitoba Health was intended or should be inferred. Data used in this study are from the Population Health Research Data Repository housed at the Manitoba Centre for Health Policy, University of Manitoba and were derived from data provided by Manitoba Health, Winnipeg Regional Health Authority, Vital Statistics, and Diagnostic Services Manitoba.

Contributors NT contributed to the conception and design of the work and interpretation of data and is responsible for the overall content as the guarantor. RHW contributed to the acquisition, statistical analysis, and interpretation of data. IH, PK, CR, and KKC contributed to the interpretation of the data. All authors contributed to the drafting of the work and critical revision of important intellectual content, final approval of the version to be published, and agreed to be accountable for all aspects of the work.

Funding The study was funded by AstraZeneca.

Disclaimer AstraZeneca had no role in the study design, collection, analysis, and interpretation of data, writing the report, or decision to submit the report for publication.

Competing interests NT has received honoraria or research support from AstraZeneca, Otsuka, and Tricida.

Patient consent for publication Not applicable.

Ethics approval This study received ethics approval from the University of Manitoba Health Research Ethics Board (ethics file number HS19580).

Provenance and peer review Not commissioned; externally peer reviewed.

Data availability statement All data relevant to the study are included in the article or uploaded as supplementary information. Data used in this article were derived from administrative health and social data as a secondary use. The data were provided under specific data sharing agreements only for approved use at Manitoba Centre for Health Policy (MCHP). The original source data is not owned by the researchers or MCHP and as such cannot be provided to a public repository. The original data source and approval for use has been noted in the acknowledgments of the article. Where necessary, source data specific to this article or project may be reviewed at MCHP with the consent of the original data providers, along with the required privacy and ethical review bodies.

Supplemental material This content has been supplied by the author(s). It has not been vetted by BMJ Publishing Group Limited (BMJ) and may not have been peer-reviewed. Any opinions or recommendations discussed are solely those of the author(s) and are not endorsed by BMJ. BMJ disclaims all liability and responsibility arising from any reliance placed on the content. Where the content includes any translated material, BMJ does not warrant the accuracy and reliability of the translations (including but not limited to local regulations, clinical guidelines, terminology, drug names and drug dosages), and is not responsible for any error and/or omissions arising from translation and adaptation or otherwise.

Open access This is an open access article distributed in accordance with the Creative Commons Attribution Non Commercial (CC BY-NC 4.0) license, which permits others to distribute, remix, adapt, build upon this work non-commercially, and license their derivative works on different terms, provided the original work is properly cited, appropriate credit is given, any changes made indicated, and the use is non-commercial. See: http://creativecommons.org/licenses/by-nc/4.0/.

\section{ORCID iDs}

Reid H Whitlock http://orcid.org/0000-0002-7046-0358

Navdeep Tangri http://orcid.org/0000-0002-5075-6370

\section{REFERENCES}

1 Fowler MJ. Microvascular and macrovascular complications of diabetes. Clinical Diabetes 2008;26:77-82.

2 Booth G, Lipscombe L, Butalia S, et al. Pharmacologic management of type 2 diabetes: 2016 interim update. Can J Diabetes 2016;40:484-6.

3 American Diabetes Association. 8. Pharmacologic Approaches to Glycemic Treatment: Standards of Medical Care in Diabetes-2018. Diabetes Care 2018;41:S73-85.

4 Thulé PM, Umpierrez G. Sulfonylureas: a new look at old therapy. Curr Diab Rep 2014;14:473.

5 Monami M, Dicembrini I, Kundisova L, et al. A meta-analysis of the hypoglycaemic risk in randomized controlled trials with sulphonylureas in patients with type 2 diabetes. Diabetes Obes Metab 2014;16:833-40.

6 Cahn A, Raz I. Emerging gliptins for type 2 diabetes. Expert Opin Emerg Drugs 2013;18:245-58.

7 Monami M, Dicembrini I, Nreu B, et al. Predictors of response to glucagon-like peptide-1 receptor agonists: a meta-analysis and systematic review of randomized controlled trials. Acta Diabetol 2017;54:1101-14.

8 Wilding J, Fernando K, Milne N, et al. Sglt2 inhibitors in type 2 diabetes management: key evidence and implications for clinical practice. Diabetes Ther 2018;9:1757-73.

9 Green JB, Bethel MA, Armstrong PW, et al. Effect of sitagliptin on cardiovascular outcomes in type 2 diabetes. N Engl J Med 2015;373:232-42.

10 Mahaffey KW, Neal B, Perkovic V, et al. Canagliflozin for primary and secondary prevention of cardiovascular events: results from the canvas program (canagliflozin cardiovascular assessment study). Circulation 2018;137:323-34.

11 Marso SP, Bain SC, Consoli A, et al. Semaglutide and cardiovascular outcomes in patients with type 2 diabetes. $N$ Engl J Med 2016;375:1834-44

12 Marso SP, Daniels GH, Brown-Frandsen K, et al. Liraglutide and cardiovascular outcomes in type 2 diabetes. N Engl J Med 2016;375:311-22.

13 Wiviott SD, Raz I, Bonaca MP, et al. Dapagliflozin and cardiovascular outcomes in type 2 diabetes. N Engl J Med 2019;380:347-57.

14 Zinman B, Wanner C, Lachin JM, et al. Empagliflozin, cardiovascular outcomes, and mortality in type 2 diabetes. $N$ Engl $\mathrm{J} \mathrm{Med}$ 2015;373:2117-28.

15 Cho YY, Cho S-I. Metformin combined with dipeptidyl peptidase-4 inhibitors or metformin combined with sulfonylureas in patients with type 2 diabetes: a real world analysis of the South Korean national cohort. Metabolism 2018;85:14-22.

16 Eriksson JW, Bodegard J, Nathanson D, et al. Sulphonylurea compared to DPP-4 inhibitors in combination with metformin carries 
increased risk of severe hypoglycemia, cardiovascular events, and all-cause mortality. Diabetes Res Clin Pract 2016;117:39-47.

17 Morgan CL, Mukherjee J, Jenkins-Jones S, et al. Combination therapy with metformin plus sulphonylureas versus metformin plus DPP-4 inhibitors: association with major adverse cardiovascular events and all-cause mortality. Diabetes Obes Metab 2014;16:977-83.

18 Ou S-M, Shih C-J, Chao P-W, et al. Effects on clinical outcomes of adding dipeptidyl peptidase-4 inhibitors versus sulfonylureas to metformin therapy in patients with type 2 diabetes mellitus. Ann Intern Med 2015;163:663-72.

$19 \mathrm{Yu} \mathrm{OHY}$, Yin H, Azoulay L. The combination of DPP-4 inhibitors versus sulfonylureas with metformin after failure of first-line treatment in the risk for major cardiovascular events and death. Can J Diabetes 2015;39:383-9.

20 Roos LL, Brownell M, Lix L, et al. From health research to social research: privacy, methods, approaches. Soc Sci Med 2008;66:117-29.

21 Roos LL, Nicol JP. A research registry: uses, development, and accuracy. J Clin Epidemiol 1999;52:39-47.

22 Smith M, Lix LM, Azimaee M, et al. Assessing the quality of administrative data for research: a framework from the Manitoba centre for health policy. J Am Med Inform Assoc 2018;25:224-9.

23 Bezin J, Girodet P-O, Rambelomanana S, et al. Choice of ICD10 codes for the identification of acute coronary syndrome in the French hospitalization database. Fundam Clin Pharmaco 2015;29:586-91.

24 Ezekowitz JA, Bakal JA, Kaul P, et al. Acute heart failure in the emergency department: short and long-term outcomes of elderly patients with heart failure. Eur J Heart Fail 2008;10:308-14.

25 Lee DS, Donovan L, Austin PC, et al. Comparison of coding of heart failure and comorbidities in administrative and clinical data for use in outcomes research. Med Care 2005;43:182-8.

26 So L, Evans D, Quan H. Icd-10 coding algorithms for defining comorbidities of acute myocardial infarction. BMC Health Serv Res 2006;6:6963-6-161.

27 Tolonen H, Salomaa V, Torppa J, et al. The validation of the Finnish hospital discharge register and causes of death register data on stroke diagnoses. Eur J Cardiovasc Prev Rehabil 2007;14:380-5.

28 Varas-Lorenzo C, Castellsague J, Stang MR, et al. Positive predictive value of ICD- 9 codes 410 and 411 in the identification of cases of acute coronary syndromes in the Saskatchewan Hospital automated database. Pharmacoepidemiol Drug Saf 2008;17:842-52.

29 Hodge MC, Dixon S, Garg AX, et al. Validation of an international statistical classification of diseases and related health problems 10th revision coding algorithm for hospital encounters with hypoglycemia. Can J Diabetes 2017;41:322-8.

30 Frier BM. Defining hypoglycaemia: what level has clinical relevance? Diabetologia 2009:52:31-4.

31 Chartier M, Dart A, Tangri N. Care of Manitobans living with chronic kidney disease. Winnipeg, MB: Manitoba Centre for Health Policy, 2015.

32 Cole SR, Hernán MA. Constructing inverse probability weights for marginal structural models. Am J Epidemiol 2008;168:656-64.

33 Austin PC. Balance diagnostics for comparing the distribution of baseline covariates between treatment groups in propensity-score matched samples. Stat Med 2009;28:3083-107.

34 Lin DY, Wei LJ, Ying Z. Checking the COX model with cumulative sums of martingale-based residuals. Biometrika 1993;80:557-72.
35 Austin PC. Optimal caliper widths for propensity-score matching when estimating differences in means and differences in proportions in observational studies. Pharm Stat 2011;10:150-61.

36 Local and global optimal propensity score matching [Internet]. Available: http://www2.sas.com/proceedings/forum2007/185-2007. pdf [Accessed 11 Oct 2019].

37 Curtis LH, Hammill BG, Eisenstein EL, et al. Using inverse probability-weighted estimators in comparative effectiveness analyses with observational databases. Med Care 2007;45:S103-7.

38 Zghebi SS, Steinke DT, Rutter MK, et al. Comparative risk of major cardiovascular events associated with second-line antidiabetic treatments: a retrospective cohort study using UK primary care data linked to hospitalization and mortality records. Diabetes Obes Metab 2016;18:916-24.

39 Nesto RW, Bell D, Bonow RO, et al. Thiazolidinedione use, fluid retention, and congestive heart failure: a consensus statement from the American heart association and American diabetes association. Diabetes Care 2004;27:256-63.

40 Ekström N, Svensson A-M, Miftaraj M, et al. Cardiovascular safety of glucose-lowering agents as add-on medication to metformin treatment in type 2 diabetes: report from the Swedish national diabetes register. Diabetes Obes Metab 2016;18:990-8.

41 Nathan DM, Buse JB, Davidson MB, et al. Medical management of hyperglycemia in type 2 diabetes: a consensus algorithm for the initiation and adjustment of therapy: a consensus statement of the American diabetes association and the European association for the study of diabetes. Diabetes Care 2009;32:193-203.

42 Karter AJ, Parker MM, Solomon MD, et al. Effect of out-of-pocket cost on medication initiation, adherence, and persistence among patients with type 2 diabetes: the diabetes study of northern California (distance). Health Serv Res 2018;53:1227-47.

43 Belsey J, Krishnarajah G. Glycaemic control and adverse events in patients with type 2 diabetes treated with metformin + sulphonylurea: a meta-analysis. Diabetes Obes Metab 2008;10 Suppl 1:1-7.

44 Mishriky BM, Cummings DM, Tanenberg RJ. The efficacy and safety of DPP4 inhibitors compared to sulfonylureas as add-on therapy to metformin in patients with type 2 diabetes: a systematic review and meta-analysis. Diabetes Res Clin Pract 2015;109:378-88.

45 U.S. Food and Drug Administration. Guidance for industry: diabetes mellitus evaluating cardiovascular risk in new antidiabetic therapies to treat type 2 diabetes [Internet]. Silver Spring, MD, 2008. Available: http://www.fda.gov/downloads/Drugs/GuidanceCompliance Regulatorylnformation/Guidances/ucm071627.pdf

46 Hurren KM, Dunham MW. Understanding the impact of commonly utilized, non-insulin, glucose-lowering drugs on body weight in patients with type 2 diabetes. Expert Opin Pharmacother 2018;19:1087-95.

47 Abdelmoneim AS, Welsh RC, Eurich DT, et al. Sulfonylurea use is associated with larger infarct size in patients with diabetes and STelevation myocardial infarction. Int J Cardiol 2016;202:126-30.

48 Bodegard J, Sundström J, Svennblad B, et al. Changes in body mass index following newly diagnosed type 2 diabetes and risk of cardiovascular mortality: a cohort study of 8486 primary-care patients. Diabetes Metab 2013;39:306-13.

49 Lee T-M, Chou T-F. Impairment of myocardial protection in type 2 diabetic patients. J Clin Endocrinol Metab 2003;88:531-7.

50 McCoy RG, Van Houten HK, Ziegenfuss JY, et al. Increased mortality of patients with diabetes reporting severe hypoglycemia. Diabetes Care 2012;35:1897-901. 